\title{
Utilization of Go Online System on Increasing Awareness in Awie Bah Akim Brand
}

\author{
Budi Harto' $^{1}$, Cecep Taufikurachman ${ }^{2}$ \\ \{budieto@gmail.com ${ }^{1}$, ctaufiq@yahoo.com ${ }^{2}$ \} \\ ${ }^{1}$ LP3I Polytechnic Bandung \\ ${ }^{2}$ EKUITAS Institute of Economic Science Bandung
}

\begin{abstract}
One of the ways that can be used by Indonesians SME's so their product can be more known by the people is by using Go Online program. Go Online is a program that make our business information written online on the web. This program can be started by the SME's themselves easily. Some suggested ways to Go Online is having a website, making a social media account, and having a platform to communicate with customers online. Supported by a good and interesting content on the website and social media, the customers will get more easy to find our business. As an SME that focused on making traditional Sundanese musical craft, Awie Bah Akim need to Go Online to increase their brand awareness and to gain new market. This program has been conducted to Awie Bah Akim successfully, 1) Awie Bah Akim can be easily searched in online world and they can introduce their product more broadly, 2) Awie Bah Akim team can manage their website, social media, and another online tools effectively, 3) Awie Bah Akim can make a good and interesting content for their owned social media and website. A few suggestions for this research is that Awie Bah Akim team still need more practice and learning so their goal is not only to get awareness, but also getting new profit. Also it will be good if their website converted to an e-commerce website to sell their crafts more easily. Or they can join an existing e-commerce website. In the future, they can also make their social media content as an ad in Facebook ads or Instagram ads to reach more customers.
\end{abstract}

Keywords: Go Online Systems, Brand Awareness, SMEs

\section{Introduction}

A lot of people now has already know about the internet. A data from Consumer Barometer survey show that the growth of internet users in Indonesia is increasing significantly. From just 29 percent in 2013, it's increasing to 56 percent in 2017 with the average users in the age 16 years old and above [2]. This thing can be caused by the Internet infrastructure getting better and the usage of smartphones who need internet connection to work. Another survey done by Consumer Barometer shows increase in smartphone user in Indonesia from 14 percent in 2013, became 60 percent in 2017 [2].

This thing makes people race in making their business go online, there are a lot of benefits that we can get if our businesses going online. Our business can be easily searched by millions of people who accessing internet anywhere and everywhere. A survey that done by JAKPAT Survey shows that 82 percent of Indonesians search about online stores through the search engine, and 45 percent of them has visiting an online store, with an average buying potential 
reaching 29 percent [7]. Go Online could be done by using a few simple tools and doesn't require a lot of cost. The first one is making a website. There are a lot of easy website builder on the internet. And then social media, a lot of people are going crazy over social media and they using it to share what happened on their life, social media could be one tools to promote our business. And then there an application to communicate like Whatsapp Business that specially made as a platform to communicate between the business owner and the customers, only with a smartphone and data package, everything can be done easily. On a day, Facebook Messenger and Whatsapp handle over 60 billion messages [9].

Imagine if going online is applied to every small medium business in Indonesia. Based on the data from the Economic Enterprise and Small Medium Enterprise Ministry, in the end of 2016, all SME's in Indonesia has contributing 60.34 percent in Gross Domestic Product (GDP). This number is increasing compared with 57.84 percent in 2015. If all the SME's in Indonesia can go online, this GDP can be increased again and the sale activity in that SME's will getting better [7]. One of the SME's that came to our attention is Awie Bah Akim. They located at Dago region in Bandung city, and they make Sundanese traditional music instrument from bamboo like Kecapi Bambu, Celempung Renteng, Rebab, Keprak, Nuansa Gludug, Keteng-Keteng, and Kendang. One of the uniqueness that Awie Bah Akim have is they make Baragbag, Baragbag is Kendang but with small in size, made from high gradeselected Bitung Bamboo that specially made to perfect an ordinary Kendang sound. Only Galengan Sora Awi, the music group from Awie Bah Akim who have Its distinctive sound, how it's placed among any other instruments, and the uniqueness of Baragbag shape.

Unfortunately, not a lot of people know all of that uniqueness that Awie Bah Akim have. A traditional music instrument maker like Awie Bah Akim should be preserved for the future generations [1]. Also, Awie Bah Akim team feels that they need a new market so they can gain their profit and they want to be more known by people.

From their problem analysis above, the solution that can be given to them are 1) Giving a go online knowledge about how to make website that contains their business information, making a social media account like Instagram Business, Official Facebook Page, and Whatsapp Business. 2) Giving a how to use a social media and website effectively. 3) Giving training about how to make good and interesting content to fill their website and social media.

The purpose of this activity are 1) Awie Bah Akim could go online, becaming easier to be found in online world, and they can introduce their product broadly 2) Awie Bah Akim could manage their own website, social media and other online tools effectively 3) Awie Bah Akim could make an interesting content to fill their website and official social media accounts.

\section{Methodological}

The methods that used in this community service is through discussions, looking for information and making a go online implementation roadmap that pictured on Picture No. 1 below. In first phase, we make an identification of what does that Awie Bah Akim need in online world, seen from profile and business potentials. Also, we're looking will this go online system have a strong impact on Awie Bah Akim brand. After everything was identified, we make what tools that Awie Bah Akim need to go online. 

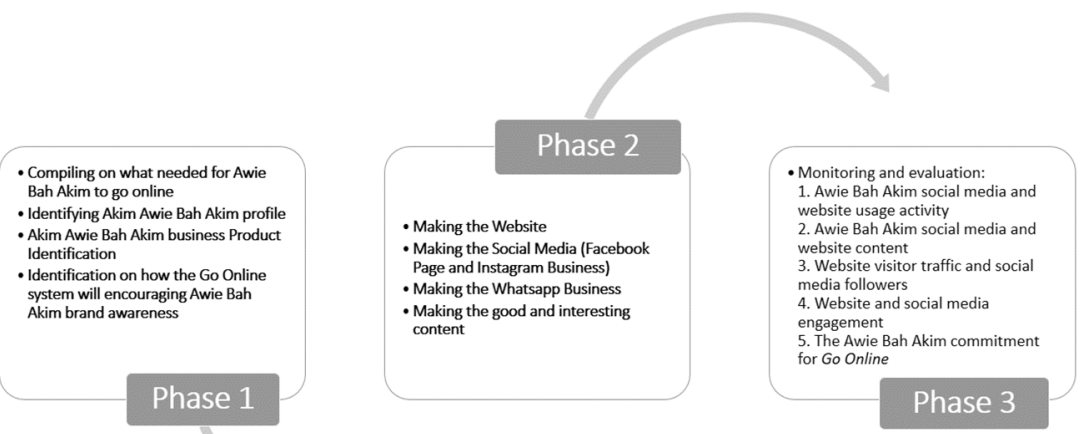

Fig 1. Awie Bah Akim's Go Online Implementation Roadmap

On the second phase, we are making all of the platform that will used, they're website, social media accounts (Facebook Page, Instagram Business), and Whatsapp Business. And in the last phase, we are doing the evaluation and monitoring towards Awie Bah Akim team, are they keep doing the go online activities after all of the service has ended.

\section{Results and Discussion}

All of the platforms and media making held on the entire month of November 2018. Here's the activities and the results from the community service:

\subsection{Awie Bah Akim Website}

The first activity that held in Awie Bah Akim go online process is making their website. For uploading content and any other thing, the backend part of their website is made as simple as possible. After the website is finished, all the contents that already available is uploaded to the website. We also make the domain custom: www.awiebahakim.com, this name will applied to any platform so it will be easier for people when they search Awie Bah Akim.

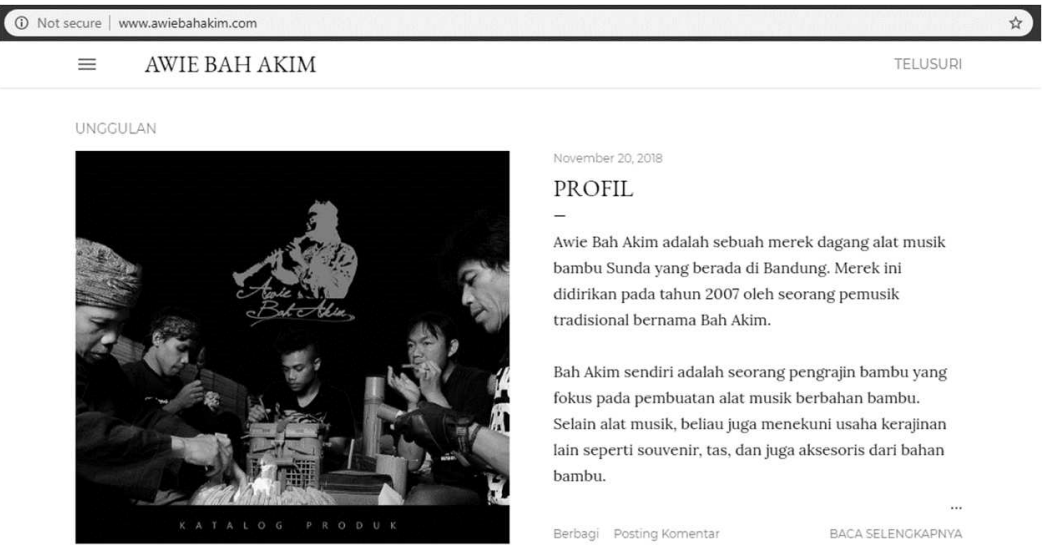

Fig 2. Awie Bah Akim's Website 
After the website is online and can be accessed, the first uploaded content is Awie Bah Akim's profile. The profile describing on how Awie Bah Akim could be established. The picture that posted is their own stock photos.

\subsection{Awie Bah Akim Social Medias}

The second part is making their social medias. We chose Instagram and Facebook because based on Hootsuite data, these social media platform is the most used by the people in the world [5].

\subsubsection{Facebook Page}

We choose Facebook Page to promoting Awie Bah Akim's business because this kind of page have the most complete features, it can post content, interacting with the followers, and showing the insights or report from the post and our interactions with the followers so we can see which content that works for the Awie Bah Akim's Facebook Page followers. Awie Bah Akim's Facebook Page can be accessed at www.facebook.com/awiebahakimm

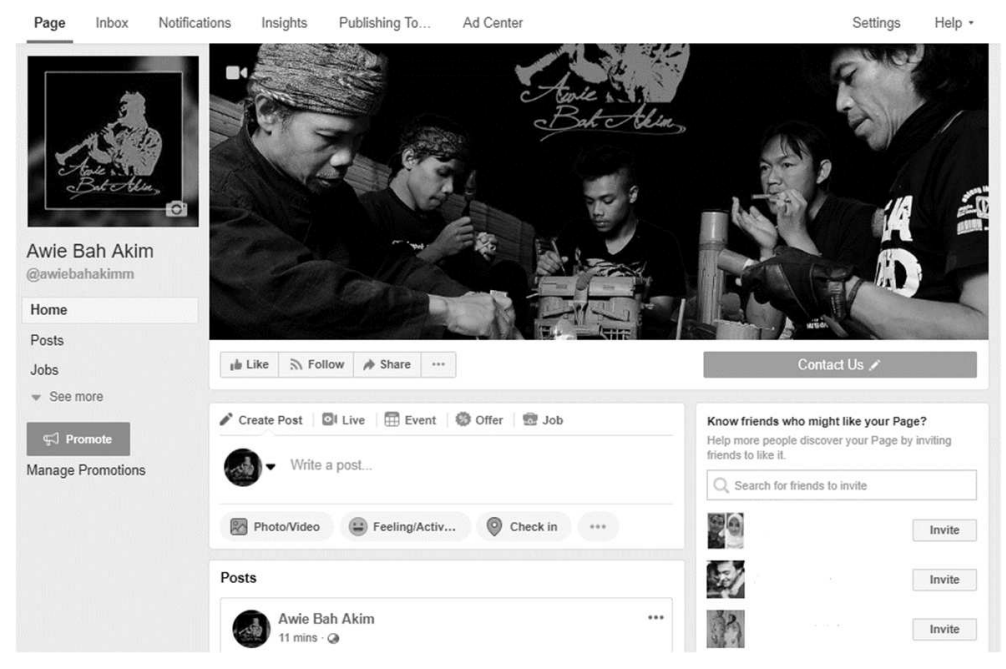

Fig 3. Awie Bah Akim's Facebook Page

\subsubsection{Instagram Business}

After finished making the Facebook Page, we continue by making Awie Bah Akim's Instagram Business. The features kind of same with Facebook Page, allowing us to see the account insights and report from our posts and interactions with the Instagram followers. This account is connected with the Facebook Page account so when the social media admin wants to upload content on Instagram, it can also be uploaded to their Facebook Page. The first content that uploaded to their social media is the same content as on their website. Awie Bah Akim's Instagram account can be viewed through: www.instagram.com/awiebahakim or by searching this username: @awiebahakim. 


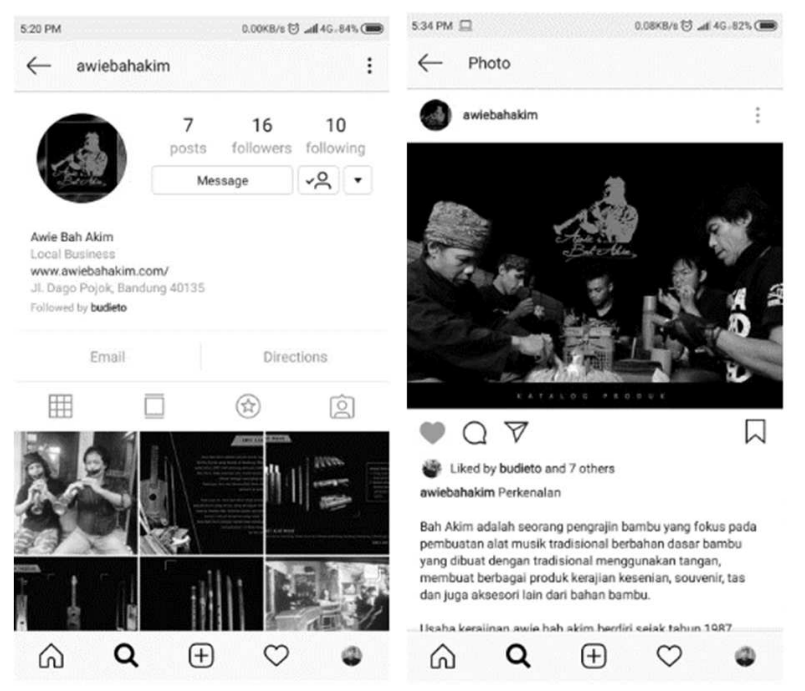

Fig 4. Awie Bah Akim Instagram Business Page

\subsection{Awie Bah Akim's Whatsapp Business}

This app is chosen because not only the Whatsapp users reaching 1,5 billion active users in the entire world, Whatsapp is also the most popular messaging app in Indonesia [4]. Easy operation, and only using a phone number when registering and communicating also became a reason why Whatsapp is chosen.

Whatsapp Business also have an interesting feature like auto reply that can answer all the unanswered customer messages. There's also template message features where we can presave answers to general questions so that when replying to general questions from customers, we can reply to them quickly.

Luckily, Awie Bah Akim's team have already using a smartphone to communicate with their customers. The next step is changing their regular Whatsapp to the Business one by downloading the Whatsapp Business on their smartphone. After the app is downloaded and registered, the number that used for Whatsapp Business is placed in all of their new social media accounts so the interested customers can quickly message them to order or to just asking about their products. 

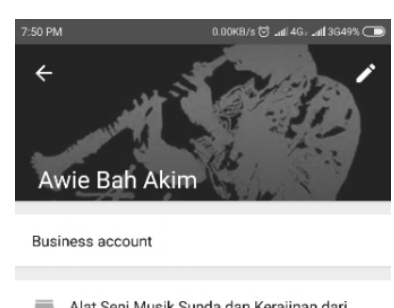

E Alat Seni Musik Sunda dan Kerajinan dari
Bambu

- Jl. Dago Pojok, Bandung

- Entertainment

(1) Monday 10:00 AM - 9:00 PM

$\square$ awiebahakim.web@gmail.com

(3) https://www.awiebahakim.com

(6) Instagram
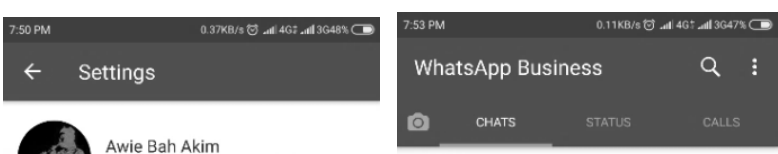

\section{0}

Budi Harto

$7.52 \mathrm{PM}$

E Business settings

9 Account

E Chats

Notifications

C Data and storage usage

ä. Invite a friend

(2) Help

Fig 5. Awie Bah Akim's Whatsapp Business Interface

In this part, we also share a few tricks on operating Whatsapp Business, like making automatic answer messages, making a few template message for faster response when chatting with customers. We also give some tips about how to facing the customers and closing the sales.

\subsection{Making a good content for Awie Bah Akim's Website and Social Media}

Making a good content is needed because to engage with the customers in online world, we need a good content that people will interested to [10], In this part, we giving a few tricks on taking product photo and video, like how to make an interesting product picture, how to make good captions and wordings for social media or website, and how to use keywords that can be applied to website and social media, so people can be more easy when searching for Awie Bah Akim.

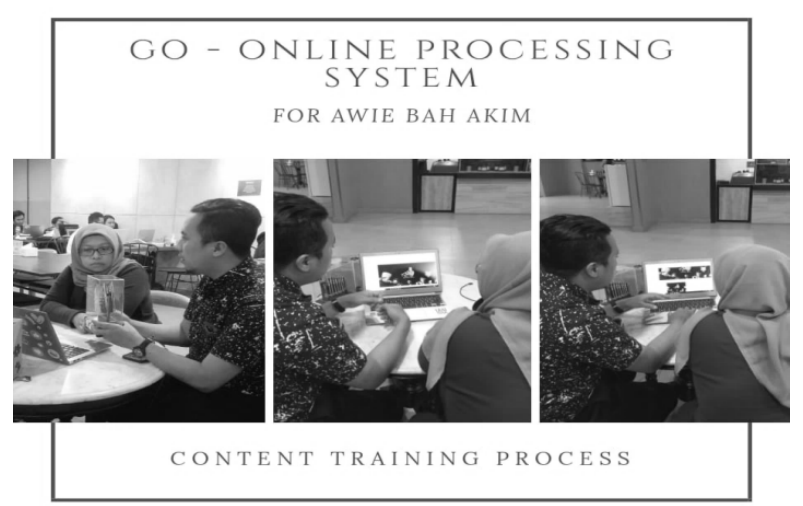

Fig 6. Awie Bah Akim Content training process 
We also introduced Awie Bah Akim teams to a few smartphones applications for making the content much more interesting, like the image processing app (Snapseed, Pixlr, Adobe Photoshop Express, Canva, etc). Video processing app (InShot, Quik, Kinemaster, etc). the team also given a few website and social media that could be a reference for them in makin good content. All the go online practices and the platform making for Awie Bah Akim was running smoothly. The team can follow all the practices and activities. In the end of the session we gave them an e-book on how to use all the platform that has been made and will they use so Awie Bah Akim go online activities will continue even when our company has ended.

\section{Conclusions}

With all the sessions has ended, Awie Bah Akim team have understand about the go online and the platform that they will use. But, on our opinion, Awie Bah Akim's team still need more practices and deeper learning about go online so all of their online activities in the future will not only for getting awareness, but also to became a new channel in making new profit [6]. In the future, it will be good if the website that has been made converted to e-commerce website to sell their product. It will be easier for people to search and shop their products conveniently [3]. Or Awie Bah Akim could make their product available in a few available ecommerce like Tokopedia, Bukalapak, etc.The social media accounts can be used further like using the ads feature. On making ads, first we need to know the habit of our audience and the people that we want to give the ads [11]. Facebook and Instagram can make our content an advertisement that could be shown to the aucience that we want, this feature require money to work, we hope Awie Bah Akim can use this feature when they have their own budget for marketing.

\section{Acknowledgments}

The authors are thankful to:

1. Allah SWT;

2. Awie Bah Akim team for the good cooperation;

3. Ibu Susi (daughter of Abah Akim);

4. LP3I Bandung Polytechnic;

5. EKUITAS Institute of Economic Science Bandung;

6. Bandung SME's and Cooperative Office, West Java;

7. Our parents and family who give their endless love and support.

For their help and support when this community service and the writing of this journal was held. 


\section{References}

[1] Bastomi. S. (1988). Apresiasi Kesenian Tradisional. Semarang: IKIP Semarang Press.

[2] Consumer Barometer Team, 2018 Internet and Social Media Survey, Consumer Barometer. 2018

[3] William H. Delone, Ephraim R. Mclean. 2014. Measuring e-Commerce Success: Applying the DeLone \& McLean Information Systems Success Model

[4] Fatimah Kartini Bohang. 2018. Pengguna Aktif Bulanan WhatsApp Tembus 1,5 Miliar.

[5] Hootsuite Team, 2018 Q4 Global Digital Statshot. Hootsuite Inc. 2018

[6] Rangkuty, Freeddy. 2002. Teknik Mengelola Brand Equity dan Strategi Pengembangan Merek. Jakarta: Gramedia Pustaka Utama.

[7] Rosa Folia. 2018. Menuju Indonesia 4.0: Besarnya Pengaruh Internet Bagi Usaha Kecil.

[8] Wahyunanda Kusuma Pertiwi. 2018. Riset Ungkap Pola Pemakaian Medsos Orang Indonesia.

[9] Smith, Kit, 2018. Social Media Statistics and Facts

[10] Carter, Rebekah. 2018. Social Media Content Strategy.

[11] Lesley Voss, 2018. Write a Better Content For Social Media 